\title{
Clinical Trials and Skin of Color: The Example of Hidradenitis Suppurativa
}

\author{
Chidubem A.V. Okeke ${ }^{a}$ Jessica D. Perry ${ }^{a} \quad$ Faith C. Simmonds ${ }^{b}$
}

Azure B. Erskine $^{\mathrm{b}}$ William D. Shipman ${ }^{\mathrm{c}}$ Janyla A. Seltzer ${ }^{\mathrm{a}}$

Marcus R. Andrews ${ }^{d}$ Arjun D. Saini ${ }^{\text {e }}$ Taylor A. Cole ${ }^{f}$ Jamilah A. Perkins ${ }^{g}$

Jane Otado $^{\mathrm{a}}$ John Kwagyan ${ }^{\mathrm{a}}$ Cassandra I.F. Collins ${ }^{\mathrm{h}}$ Ginette A. Okoye $^{\mathrm{i}}$

Angel S. Byrdi

${ }^{a}$ Howard University College of Medicine, Washington, DC, USA; ${ }^{b}$ Howard University, Washington, DC, USA;

'Yale-New Haven Hospital, New Haven, CT, USA; ${ }^{d}$ Department of Health Behaviors and Health Education, University of Michigan, Ann Arbor, MI, USA; 'Department of Dermatology, Howard University Hospital, Washington, DC, USA; ${ }^{f}$ Charles R. Drew/UCLA Medical Education Program, Los Angeles, CA, USA; ${ }^{9}$ Meharry Medical College, Nashville, TN, USA; hUniversity of Miami Miller School of Medicine, Miami, FL, USA; 'Department of Dermatology, Howard University College of Medicine, Washington, DC, USA

\section{Introduction}

Despite the recent momentum of skin of color conversations in dermatology, adequate research on skin of color diseases is still lacking and African Americans/Blacks are often underrepresented in clinical trials. This underrepresentation is especially glaring in hidradenitis suppurativa (HS) clinical trials [1]. HS is a chronic inflammatory skin condition that commonly affects intertriginous areas and is characterized by painful nodules, draining sinus tracts, and hypertrophic scarring [2]. A recent systematic review focusing on racial populations reports the average prevalence rate of HS as highest in African Americans compared to both Whites and Hispanics/Latinos [3]. Additionally, a study evaluating $47,690 \mathrm{HS}$ patients across the USA found that the disease affects $54.1 \%(25,780 / 47,690)$ Whites compared to $32.6 \%$ $(15,540 / 47,690)$ African Americans; however, when standardized to the US population, the adjusted prevalence of HS was shown to disproportionately affect African American patients with a three-fold increase compared to Whites [4]. Taking into account the wide distri- bution of populations affected, African Americans are minimally included in HS clinical trials [1]. Of 15 phase II and III HS trials published over the last 12 years (20072019), $68 \%$ of the participants were Caucasian while only $14.0 \%$ were of African descent [1]. This disparity hinders our complete understanding of the therapeutic effects and responses in African Americans, which may lead to the development and use of HS treatments that are neither reflective nor fully applicable to diverse patient populations. The lack of racial and ethnic diversity in HS clinical trials has been highlighted in the literature [1], but barriers and possible explanations are still unclear. Herein we explore the lack of African American representation in these studies by examining the clinical trial locations within the USA and by discussing potential barriers to African American inclusion.

We searched the Clinicaltrials.gov website using the search term "hidradenitis suppurativa" and included clinical trials that had started between January 2008 and May 2020. We included studies with trial sites worldwide; however, we excluded those without US locations and those that did not report subjects' racial demographics. karger@karger.com

(C) 2021 S. Karger AG, Basel

www.karger.com/drm
Correspondence to:

Angel S. Byrd, angel_byrd@alumni.brown.edu 
There were 13 clinical trials taking place at 96 different locations in the USA (Table 1; online suppl. Fig. 1; see www.karger.com/doi/10.1159/000516467 for all online suppl. material). In these trials, $14.9 \%$ of participants were classified as Black, African American, or of African descent (Table 1; online suppl. Fig. 1), similar to the previously reported rate in global HS clinical trials [1].

We hypothesized that this disparity could be related to the demographics of the US cities in which the trials were conducted. To explore this possibility, we compared clinical trial locations and the racial distribution of the US population according to the 2010 census data (www.census.gov/quickfacts). Interestingly, almost half (49\%) of the US trial sites were located in zip codes with moderate $(12.6-49.9 \%)$ to high ( $>50 \%)$ African American populations, whereas $43.8 \%$ were located in areas with low (012.5\%) African American populations. This suggests that the demographics of clinical trial sites do not adequately account for the low representation of African Americans in HS clinical trials conducted in the USA. However, there may be other barriers that lead to suboptimal recruitment of African American patients into these trials.

\section{Barriers: Patient Perspective}

African American patients may be distrustful of clinical research and avoid participation due to a fear of exploitation. This mistrust of the medical community may prevent African American patients from communicating with their physicians and limit their opportunities to be exposed to research trial information [5]. For some patients, the time commitment, lack of transportation, and financial burden are additional obstacles to enrollment [5]. In addition, African American patients may have multiple comorbidities that potentially make them ineligible for HS trials. For example, African Americans are two times more likely than White individuals to develop diabetes [6]. Although comorbidities were not a common exclusion criterion, the Etanercept study (NCT00107991) excluded patients with severe comorbidities such as diabetes mellitus requiring insulin or uncontrolled hypertension.

\section{Barriers: Physician Perspective}

Implicit and explicit forms of bias among physicians may also contribute to low African American enrollment in HS clinical trials [7]. Prior research has shown that negative stereotypes among referring physicians may make them less likely to offer clinical trials to African American patients [7]. Some clinicians may assume that African American patients are unwilling to participate in research studies [7]. Consequently, they may not offer these clinical trial opportunities to potential candidates [7]. Providers (clinicians/principal investigators) also spend less time explaining the benefits and adverse effects of clinical trials to African American patients [5]. This lack of communication and cultural competency can exacerbate patient concerns, leading to their refusal to participate [5].

\section{Discussion}

Our findings demonstrate that although HS trials have been conducted in US regions with diverse populations, African American patients with HS are poorly represented in these studies. This disparity hinders our complete understanding of the disease and its impact on different populations, and decreases African American patients' access to potentially effective new therapies.

Establishing racial and ethnic diversity in dermatology is an important step in addressing this disparity. Despite a $13 \%$ African American population in the USA, only $3 \%$ of US dermatologists identify as African American [8]. African American and other minority patients feel more comfortable expressing their concerns with physicians of the same race/ethnicity or those who have had similar shared experiences $[9,10]$. Minority physicians may have a better understanding of the obstacles that prevent African Americans from participating in HS clinical trials and may therefore help close this gap. In addition, diversifying training materials used during medical school and dermatology residency may improve dermatologists' understanding of how conditions present differently on darker skin tones, which may subsequently lead to earlier diagnoses and potentially more referrals to clinical trials.

It is well known that physician bias contributes to health disparities. The American Academy of Family Physicians has developed the Implicit Bias Training Guide (aafp.org), which equips health care professionals with strategies to recognize and address their biases. Physicians who are cognizant of their biases may adjust their behaviors, including offering more clinical trial opportunities to African American patients. We encourage physicians, especially dermatologists, to consult this guide to improve patient's access to HS clinical trials. 


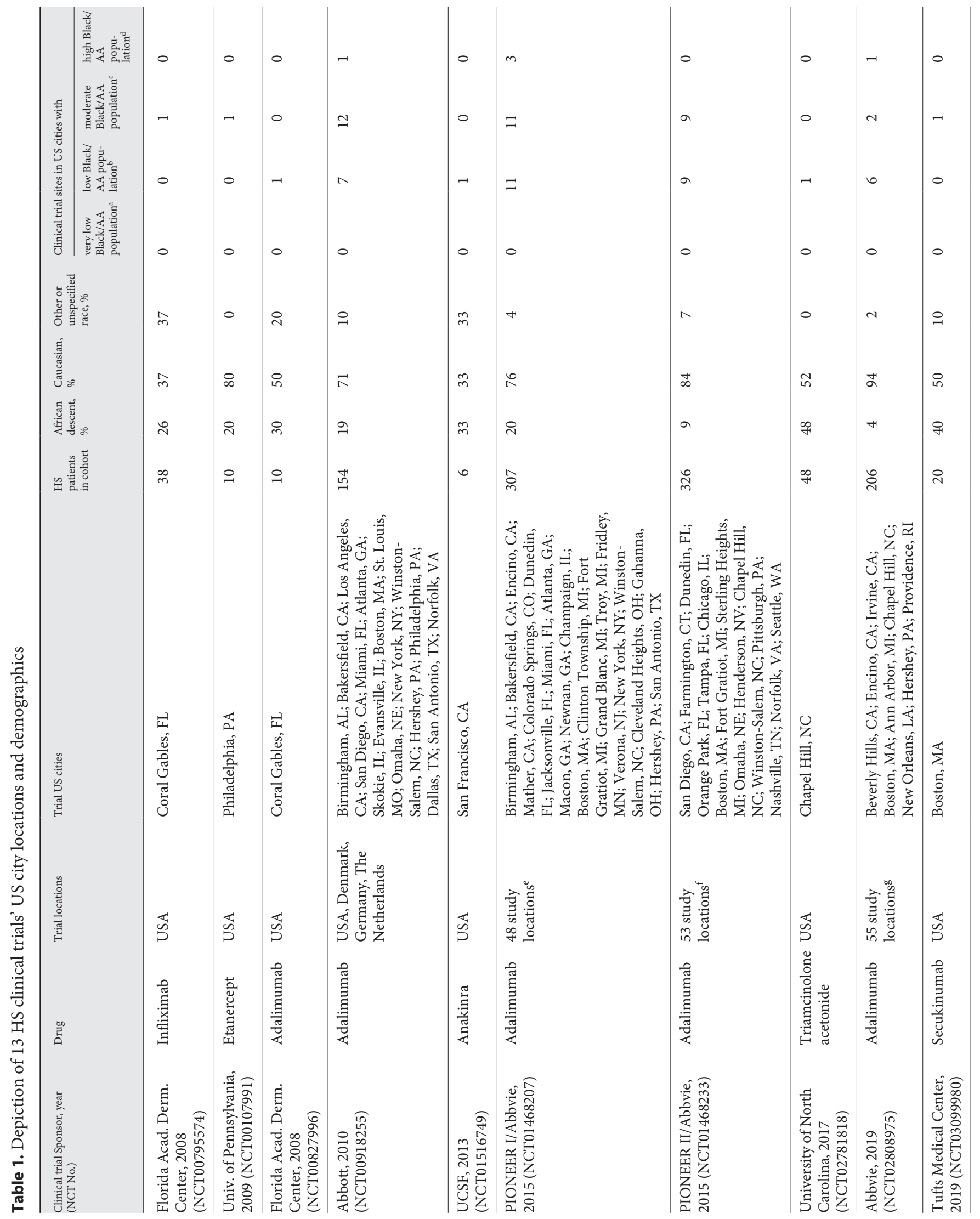




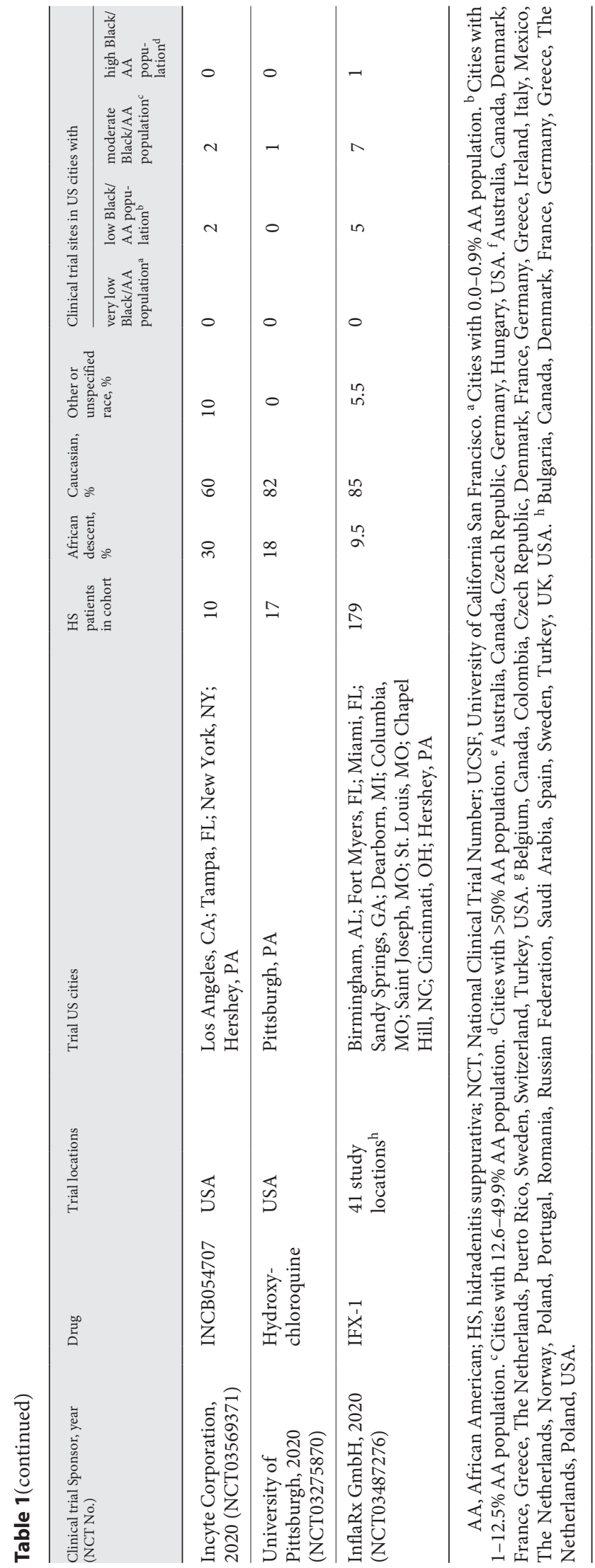

Researchers should expand their recruitment efforts by collaborating with community-based organizations. Generally, African American communities are more likely to trust information received from their local community organizations [5] such as churches, community centers, and support groups. These organizations may have stronger connections to this population and may be regarded as trusted sources of information. Specifically, inperson and online HS patient support groups may provide a safe space for patients to receive accurate information and support as they decide whether or not to participate in clinical trials.

\section{Limitations and Opportunities in International \\ Clinical Trials}

The limitation of our study is that the complete racial demographics and recruitment methods were not provided for each clinical trial site. Specifically, studies conducted globally did not state whether the Black, African American, or African descent participants were selected from the USA or from other countries.

There are international biases that should be mentioned. Due to the nondiverse areas of some geographical regions, the representation of African Americans may be minimal. This highlights the imperative need for clinical trial sites to be carefully selected both internationally and within the USA. Additionally, international institutions could foster collaborations with US institutions to ensure inclusion of African Americans and other diverse patient populations.

As we work to eliminate health disparities in the USA, we encourage physicians, researchers, and patients to promote and advocate racial diversity within clinical trial participants. This will contribute to improving access to care for underserved and underrepresented populations, resulting in an improved understanding of HS and other challenging dermatological diseases.

\section{Key Message}

Racial demographics do not adequately explain the disparity in African American enrollment in HS clinical trials.

\section{Conflict of Interest Statement}

The authors have no conflicts of interest to declare. 


\section{Funding Sources}

No funding was received for this study.

\section{Author Contributions}

C.A.V. Okeke, J.D. Perry, W.D. Shipman, T.A. Cole, G.A. Okoye, and A.S. Byrd identified the gap in the field, conceptualized, and were involved in the overall design, and drafted the man- uscript. C.A.V. Okeke, J.D. Perry, F.C. Simmonds, A.B. Erskine, W.D. Shipman, J.A. Seltzer, M.R. Andrews, A.D. Saini, and A.S. Byrd acquired and analyzed data. C.A.V. Okeke, J.D. Perry, F.C. Simmonds, A.B. Erskine, W.D. Shipman, J.A. Seltzer, M.R. Andrews, A.D. Saini, T.A. Cole, J.A. Perkins, J. Otado, J. Kwagyan, C.I.F. Collins, G.A. Okoye, and A.S. Byrd provided critical review of the data and data interpretation, manuscript revisions, and final approval for publication.

\section{References}

1 Price KN, Hsiao JL, Shi VY. Race and ethnicity gaps in global hidradenitis suppurativa clinical trials. Dermatology. 2021;237(1):97102.

2 Sabat R, Jemec GBE, Matusiak L, Kimball AB, Prens E, Wolk K. Hidradenitis suppurativa. Nat Rev Dis Primers. 2020;6(1):18.

3 Sachdeva M, Shah M, Alavi A. Race-specific prevalence of hidradenitis suppurativa. J $\mathrm{Cu}-$ tan Med Surg. 2021 Mar-Apr;25(2):177-87.

4 Garg A, Kirby JS, Lavian J, Lin G, Strunk A. Sex- and age-adjusted population analysis of prevalence estimates for hidradenitis suppurativa in the United States. JAMA Dermatol. 2017;153(8):760-4.
5 Otado J, Kwagyan J, Edwards D, Ukaegbu A, Rockcliffe F, Osafo N. Culturally competent strategies for recruitment and retention of African American populations into clinical trials. Clin Transl Sci. 2015;8(5):460-6.

6 Bancks MP, Kershaw K, Carson AP, GordonLarsen P, Schreiner PJ, Carnethon MR. Association of modifiable risk factors in young adulthood with racial disparity in incident type 2 diabetes during middle adulthood. JAMA. 2017;318(24):2457-65.

7 Niranjan SJ, Martin MY, Fouad MN, Vickers SM, Wenzel JA, Cook ED, et al. Bias and stereotyping among research and clinical professionals: perspectives on minority recruitment for oncology clinical trials. Cancer. 2020; 126(9):1958-68.
8 Oyesanya T, Grossberg AL, Okoye GA. Increasing minority representation in the dermatology department: the Johns Hopkins experience. JAMA Dermatol. 2018;154(10): $1133-4$.

9 Harvey VM, Ozoemena U, Paul J, Beydoun HA, Clemetson NN, Okoye GA. Patient-provider communication, concordance, and ratings of care in dermatology: results of a crosssectional study. Dermatol Online J. 2016; 22(11):13030.

10 Takeshita J, Wang S, Loren AW, Mitra N, Shults J, Shin DB, et al. Association of racial/ ethnic and gender concordance between patients and physicians with patient experience ratings. JAMA Netw Open. 2020;3(11): e2024583. 